\title{
Synthesis, Spectral Study and Crystal Structure of a Fluorescein Derivative, $p$-Methoxycarbonylphenyl Fluorone
}

\author{
Shinichiro Kamino, Yuko Kawamae, Megumi Ijyuin, Shingo Takada, Takako Yamaguchi, \\ Mitsunobu DoI, and Yoshikazu FustT**
}

Osaka University of Pharamaceutical Sciences; Takatsuki 569-1094, Japan.

Received June 2, 2009; accepted August 17, 2009; published online September 17, 2009

\begin{abstract}
Protolytic equilibria of $p$-methoxycarbonylphenyl fluorone (PMCPF) in aqueous solutions were studied by spectrophotometry, and the species of PMCPF were determined. We describe for the first time the X-ray structure of the proton acceptor form of PMCPF.
\end{abstract}

Key words $\quad p$-methoxycarbonylphenyl fluorone; synthesis; spectral study; acid dissociation exponent; crystal structure

Fluorescein derivatives have been used widely in chemical biology, material sciences, and other scientific disciplines owing to their brightness, high quantum yields, and biocompatibility. ${ }^{1,2)}$ Fluorescein exists as a complex organic solid that can be categorized into three forms: (I) the lactonoid form, which is a colorless solid; (II) the quinoid form, a red solid; and (III) the zwitterionic form, a yellow solid. ${ }^{3-7)}$ In aqueous solutions, the behavior of fluorescein is more complicated. ${ }^{8-11)}$ Therefore, an understanding of the electronic and physical properties, as well as the photo properties, of fluorescein is necessary to elucidate its structure. The design of new derivatives of fluorescein would be facilitated if we could predict the properties of this compound and its derivatives.

We have reported previously the crystal structure of $o$-sulfophenylfluorone (SPF). ${ }^{12)}$ SPF is a sulfofluorescein molecule that does not form the lactonoid structure. SPF can exist in the zwitterionic form due to proton migration from the benzene sulfonic acid moiety attached to the xanthene moiety, through intermolecular hydrogen bonding. Based on this, we devised a strategy where the structure would most likely be not the lactonoid form but the quinoid form, by introducing a protecting group into benzoic acid to prevent proton dissociation, and proceeded to investigate the protolytic equilibria in aqueous solutions and the crystal structure of synthesized $p$-methoxycarbonylphenyl fluorone (PMCPF), shown in Fig. 1.

In this work, the absorption spectra of PMCPF in $0.2 \mathrm{~mol} / 1$ citrate buffers of integral $\mathrm{pH}$ numbers ranging from 0 to 10 were measured and $\mathrm{p} K_{\mathrm{a}}$ values of PMCPF were estimated based on the spectra and their well-detailed analysis. Protolytic equilibria in aqueous solutions of PMCPF were studied using spectrophotometry. Then, identical spectra of PMCPF with quinoid form was obtained from spectra of PMCPF at $\mathrm{pH} 3$ and $\mathrm{pH} 4$ by using these $\mathrm{p} K_{\mathrm{a}}$ values and calculation. Although the xanthene moiety of fluorescein has been analyzed by spectroscopy, there is no X-ray crystallo-

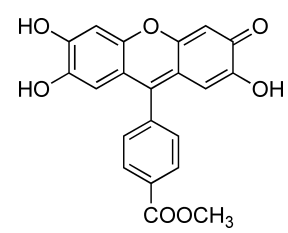

Fig. 1. Structure of PMCPF graphic evidence that it can act as a proton acceptor. ${ }^{9)}$ Finally, we isolated the proton acceptor form of a fluorescein by PMCPF, and, for the first time, revealed the molecular structure by X-ray crystallographic analysis.

\section{Experimental}

Apparatus and Reagents Regents were purchased from Wako or Nacalai Tesque or TCI Japan. All other solvents were used without further purification.

${ }^{1} \mathrm{H}$ - and ${ }^{13} \mathrm{C}$-NMR spectra were recorded using $500 \mathrm{MHz}$ spectrometers. Solvents used for NMR spectra were one of the following DMSO- $d_{6}$ with tetramethylsilane (TMS) as the internal standard. Mass spectra were acquired using JMX-700 (2) (JEOL. Co. Ltd.) MS instrument. UV-vis spectra were collected on Shimadzu UV-1700 spectrophotometer at room temperature using $1 \mathrm{~cm}$ quarts cuvette. A Horiba F-55 glassware $\mathrm{pH}$ meter was used for the $\mathrm{pH}$ measurements.

Synthetic Route to $p$-Methoxycarbonylphenyl Fluorone (PMCPF) $p$ Carboxyphenyl Fluorone (PCPF): To a solution of 1,2,4-benzenetrioltriacetate $(5.0 \mathrm{~g}, 22.0 \mathrm{mmol}), p$-carboxybenzaldehyde $(1.6 \mathrm{~g}, 11.0 \mathrm{mmol})$ was added in $2.0 \mathrm{ml}$ of $\mathrm{MeSO}_{3} \mathrm{H}$ and $200 \mathrm{ml}$ methanol solutions and the solution was heated to reflux at $80^{\circ} \mathrm{C}$ for $2 \mathrm{~d}$ and then quenched by addition of ammonium chloride solution. The crude product was isolated by removal of the ethanol under reduced pressure. Five w/v \% sodium hydroxide was added to the products and dissolved. To a sodium hydroxide solution, glacial acetic acid was slowly added in ice-bath adjusting $\mathrm{pH} 3.0$ to precipitate red solids. The crude solids were filtered, washed well with water and dried vacuum. Acetic anhydride $(2.0 \mathrm{~g}, 20 \mathrm{mmol})$ was added to a solution of the crude compound $(510 \mathrm{mg})$, triethylamine $(2.0 \mathrm{~g}, 20 \mathrm{mmol})$ and a bit of 4-dimethylaminopyridine (DMAP) in $\mathrm{CH}_{2} \mathrm{Cl}_{2}(30 \mathrm{ml})$ at $50{ }^{\circ} \mathrm{C}$. The reaction was monitored by TLC. The mixture was poured into ammonium chloride solution and extracted with $\mathrm{CH}_{2} \mathrm{Cl}_{2}$ three times. The organic layers were washed with brine, dried over $\mathrm{MgSO}_{4}$ and evaporated to give the crude product. This was purified by silica gel column chromatography (eluent: $\mathrm{CH}_{2} \mathrm{Cl}_{2}: \mathrm{MeOH}=$ $30: 1, R f=0.29$ ) to obtain the acetylation products. The product was dissolved in $40 \mathrm{ml}$ of $2 \mathrm{M} \mathrm{KOH}$ in methanol and $20 \mathrm{ml}$ water was added. The mixture was stirred at about $50^{\circ} \mathrm{C}$ for $2 \mathrm{~h}$. After addition of $40 \mathrm{ml}$ water, the methanol was removed by distillation. Acidification with glacial acetic acid and collection of the precipitate by filtration and drying gave the pure PCPF as red powder. Yield: $115 \mathrm{mg}(3.2 \%) ;{ }^{1} \mathrm{H}-\mathrm{NMR}$ (DMSO- $\left.d_{6}, 500 \mathrm{MHz}\right) \delta$ : $8.19(\mathrm{~d}, 2 \mathrm{H}, J=6.4 \mathrm{~Hz}), 7.58(\mathrm{~d}, 2 \mathrm{H}, J=6.6 \mathrm{~Hz}), 6.7(\mathrm{~s}, 2 \mathrm{H}), 6.31(\mathrm{~s}, 2 \mathrm{H})$. ${ }^{13} \mathrm{C}-\mathrm{NMR}$ (DMSO- $\left.d_{6}, 500 \mathrm{MHz}\right) \delta: 166.90,151.85,147.63,144.47,138.11$, 131.53, 129.50, 114.34, 106.04, 102.16. HR-MS (FAB): Calcd for $\mathrm{C}_{20} \mathrm{H}_{12} \mathrm{O}_{7}$ $(\mathrm{M}+\mathrm{H}): 365.0661$; Found: 365.0658 .

p-Methoxycarbonylphenyl fluorone (PMCPF): PCPF (160 mg, $0.44 \mathrm{mmol}$ ) was dissolved in $50 \mathrm{ml}$ of $\mathrm{MeOH}$ and a catalytic amount of methanesulfuric acid was added. The reaction mixture was heated at reflux $12 \mathrm{~h}$ with stirring and then quenched by addition of ammonium chloride solution. The solvent was removed on the rotary evaporator. $5 \mathrm{w} / \mathrm{v} \%$ sodium hydroxide was added to the products and dissolved. To a sodium hydroxide solution, glacial acetic acid was slowly added in ice-bath adjusting pH 3.0 to precipitate red solids. Yield: $165 \mathrm{mg}(98 \%) ;{ }^{1} \mathrm{H}-\mathrm{NMR}\left(\mathrm{DMSO}-d_{6}, 500 \mathrm{MHz}\right)$ $\delta$ : 9.47 (brs, $1 \mathrm{H}), 8.23(\mathrm{dd}, 2 \mathrm{H}, J=8.5,2.1 \mathrm{~Hz}), 7.61(\mathrm{dd}, 2 \mathrm{H}, J=8.5$, $1.8 \mathrm{~Hz}), 6.73(\mathrm{brs}, 1 \mathrm{H}), 6.31(\mathrm{~s}, 1 \mathrm{H}), 3.94(\mathrm{~s}, 3 \mathrm{H}) .{ }^{13} \mathrm{C}-\mathrm{NMR}$ (DMSO-d $d_{6}$, $500 \mathrm{MHz}) \delta$ : $165.75,152.73,147.27,144.22,138.55,130.09,129.73$, 
129.41, 102.34, 52.35. HR-MS (FAB): Calcd for $\mathrm{C}_{21} \mathrm{H}_{15} \mathrm{O}_{7}(\mathrm{M}+\mathrm{H})$ : 379.0818; Found: 379.0829 .

\section{Results and Discussion}

Spectral Study The absorbance and fluorescence spectrum of $6.8 \times 10^{-6} \mathrm{~mol} / 1 \mathrm{PMCPF}$ in $0.2 \mathrm{~mol} / 1$ citrate buffers of integral $\mathrm{pH}$ values ranging from 0 to 10 were measured at ionic strength of $1.0 \mathrm{~mol} / 1 \mathrm{KCl}$ (Fig. 2). PMCPF is expected to exist in various forms based on its $\mathrm{pH}$-dependent response in aqueous solution, following the sequence (I) univalent cation, (II) neutral form, (III) univalent anion, (IV) bivalent anion, and so on.

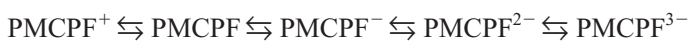

The $\mathrm{p} K_{\mathrm{a}}$ values of PMCPF in aqueous solutions were deter-

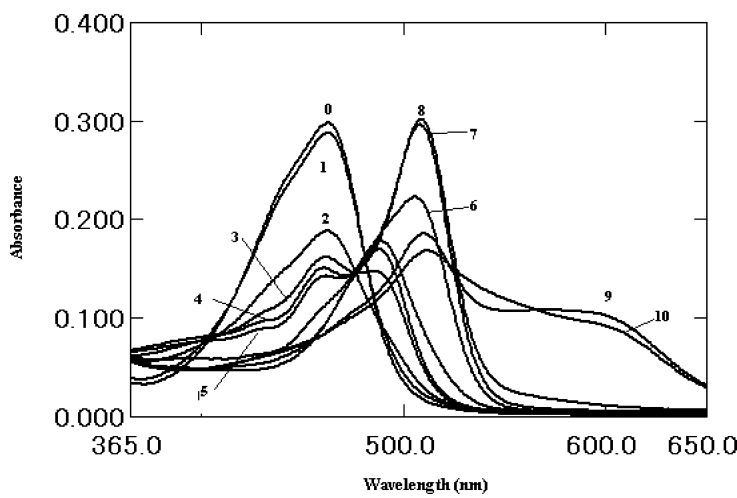

Fig. 2. Absorption Spectra of PMCPF

$\mathrm{pH}$ values of solutions are given on the peaks. The final concentration of PMCPF is $4.8 \times 10^{-6} \mathrm{~mol} / 1$ mined based on following method. ${ }^{14)}$

Estimation of $\mathbf{p} K_{\mathrm{a}}$ Values of PMCPF $\mathrm{p} K_{\mathrm{a} 1}$ Value of PMCPF: $\mathrm{p} K_{\mathrm{a} 1}$ of PMCPF was measured spectrophotometrically.

$$
\begin{gathered}
\mathrm{PMCPF}^{+} \leftrightarrows \mathrm{PMCPF}+\mathrm{H}^{+} \\
K_{1}=\frac{\left[\mathrm{H}^{+}\right][\mathrm{PMCPF}]}{\left[\mathrm{PMCPF}^{+}\right]}
\end{gathered}
$$

Calculating Eq. 2 logarithmically, we obtain

$$
\mathrm{pH}=\mathrm{p} K_{\mathrm{a} 1}-\log \frac{\left[\mathrm{PMCPF}^{+}\right]}{[\mathrm{PMCPF}]}
$$

The absorption spectra were measured in detail between $\mathrm{pH}$ 0 and $\mathrm{pH} 4.0$ (Fig. 3a). We predict that the dissociation species is in the univalent cation form, $\mathrm{PMCPF}^{+}$, at $\mathrm{pH} 0.16$, and the absorbance at $462 \mathrm{~nm}$ is indicated in $A_{\mathrm{PMCPF}^{+}}$. Assuming that the species at $\mathrm{pH} 3.50$ is in the neutral form, PMCPF, its absorbance is indicated in $A_{\mathrm{PMCPF}}$. Then, the absorbance, $A$, between both $\mathrm{pH}$ values indicates a mixture of $\mathrm{PMCPF}^{+}$and PMCPF. When $\left[\mathrm{PMCPF}^{+}\right]$and $[\mathrm{PMCPF}]$ in Eq. 3 are replaced with absorbance, we get

$$
\mathrm{pH}=\mathrm{p} K_{\mathrm{a} 1}-\log \frac{\left[A-A_{\mathrm{PMCPF}}\right]}{\left[A_{\mathrm{PMCPF}^{+}}-A\right]}
$$

The $\mathrm{p} K_{\mathrm{a} 1}$ value of $\mathrm{pH} 0.16-3.5$ solutions can be obtained by measuring the absorbance at $462 \mathrm{~nm}$. Hence, $\mathrm{p} K_{\mathrm{a} 1}=1.84$ was calculated from Eq. 4, as shown in Fig. 3 b.

$\mathrm{p} K_{\mathrm{a} 2}$ Value of PMCPF: $\mathrm{p} K_{\mathrm{a} 2}$ of PMCPF was measured spectrophotometrically as well as $\mathrm{p} K_{\mathrm{a} 1}$.

$\mathrm{PMCPF} \leftrightarrows \mathrm{PMCPF}^{-}+\mathrm{H}^{+}$

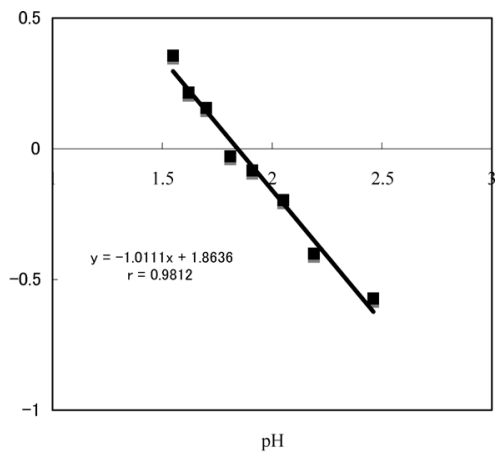

(b)

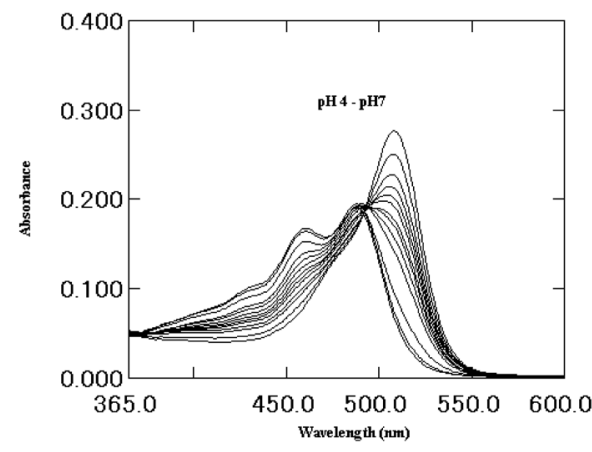

(c)

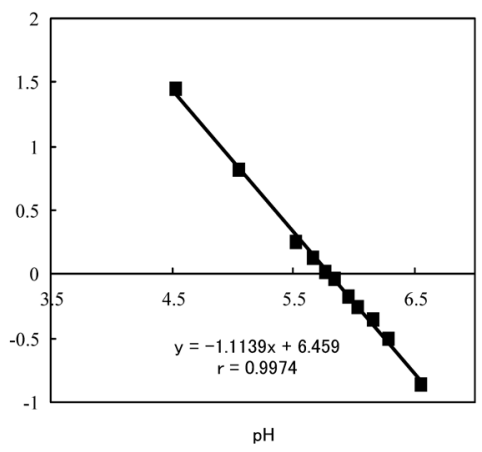

(d)

Fig. 3. (a) Absorption Spectra of PMCPF between $\mathrm{pH} 0-4.0$, (b) Determination of $\mathrm{p} K_{\mathrm{a} 1}, L=\left(A-A_{\mathrm{PMCPF}}\right), D=\left(A_{\mathrm{PMCPF}^{+}}-A\right)$, (c) Absorption Spectra of $\mathrm{PMCPF}$ between $\mathrm{pH} 4.0-7.0$ and (d) Determination of $\mathrm{p} K_{\mathrm{a} 2}, L=\left(A-A_{\mathrm{PMCPF}^{-}}\right), D=\left(A_{\mathrm{PMCPF}^{-}}-A\right)$ 
The absorption spectra were measured between $\mathrm{pH} 4$ and $\mathrm{pH}$ 8.5 (Fig. 3c). We predict that the dissociation species is in the neutral form, PMCPF, at $\mathrm{pH} 4.1$, and the absorbance at $508 \mathrm{~nm}$ is expressed as $A_{\mathrm{PMCPF}}$. Assuming that the species at $\mathrm{pH} 7.0$ is in the univalent anion form, $\mathrm{PMCPF}^{-}$, its absorbance is expressed as $A_{\mathrm{PMCPF}^{-}}$. Then, the absorbance, $A$, between both $\mathrm{pH}$ values indicates an absorbance of mixture of $\mathrm{PMCPF}$ and $\mathrm{PMCPF}^{-}$. When [PMCPF] and $\left[\mathrm{PMCPF}^{-}\right]$in Henderson-Hasselbalch equation are replaced with absorbance, we get

$$
\mathrm{pH}=\mathrm{p} K_{\mathrm{a} 2}-\log \frac{\left[A-A_{\mathrm{PMCPF}}\right]}{\left[A_{\mathrm{PMCPF}}-A\right]}
$$

The $\mathrm{p} K_{\mathrm{a} 2}$ value of $\mathrm{pH} 4.0-7.0$ solutions can be obtained by measuring the absorbance at $508 \mathrm{~nm}$. Hence, $\mathrm{p} K_{\mathrm{a} 2}=5.80$ was calculated from Eq. 6, as shown in Fig. 3d.

Calculation of Molar Fraction from $\mathbf{p} \boldsymbol{K}_{\mathrm{a}}$ Values Molar fraction of PMCPF in aqueous solutions were calculated following the literature. ${ }^{9)}$

$$
\begin{aligned}
& {\left[\mathrm{H}^{+}\right][\mathrm{PMCPF}] /\left[\mathrm{PMCPF}^{+}\right]=10^{-\mathrm{p} K_{\mathrm{al}}}} \\
& {\left[\mathrm{H}^{+}\right]\left[\mathrm{PMCPF}^{-}\right] /[\mathrm{PMCPF}]=10^{-\mathrm{p} K_{\mathrm{a} 2}}}
\end{aligned}
$$

Then,

$$
\left[\mathrm{H}^{+}\right]^{2}+K_{1}\left[\mathrm{H}^{+}\right]+K_{1} K_{2}=\Sigma \quad\left(K_{1}, K_{2} ; \text { equilibrium constants }\right) .
$$

We obtained the molar fraction from equations,

$$
\begin{aligned}
& {\left[\mathrm{PMCPF}^{+}\right] / C_{\text {total }}=\left[\mathrm{H}^{+}\right]^{2} / \Sigma} \\
& {[\mathrm{PMCPF}] / C_{\text {total }}=\left[\mathrm{H}^{+}\right] \times 10^{-\mathrm{p} K_{\mathrm{at}} / \Sigma}} \\
& {\left[\mathrm{PMCPF}^{-}\right] / C_{\text {total }}=10^{-\mathrm{p} K_{\mathrm{a} 2}-\mathrm{p} K_{\mathrm{a} 3} / \Sigma}} \\
& \left(C_{\text {total }}=6.8 \times 10^{-6} \mathrm{~mol} / 1, \text { total concentration }\right)
\end{aligned}
$$

Absorption Spectrum of PMCPF with Quinoid Form PMCPF can not exist as quinoid or zwitterionic form but as quinoid form in the neutral structure. The elucidation of absorption spectrum of the neutral form would therefore identify that of quinoid form.

[PMCPF] reached the maximum concentration at $\mathrm{pH} 3.8$ of average value of $\mathrm{p} K_{\mathrm{a} 1}$ and $\mathrm{p} K_{\mathrm{a} 2}$. After the selection of $\mathrm{pH}$ 3.0 and $\mathrm{pH} 4.0$, the absorbance $A_{3}$ of $\mathrm{pH} 3.0, A_{0}$ of $\mathrm{pH} 0$ and $A_{7}$ of pH 7.0 were measured at arbitrary wavelength, respectively. Assuming that the absorbance $A_{3}^{\prime}$ was maximum concentration of $[\mathrm{PMCPF}], A_{3}^{\prime}$ could be calculated from following the equation.

$$
A_{3}^{\prime}=\frac{A_{3}-A_{0}\left[\mathrm{PMCPF}^{+}\right] / C_{\text {total }}-A_{7}\left[\mathrm{PMCPF}^{-}\right] / C_{\text {total }}}{[\mathrm{PMCPF}] / C_{\text {total }}}
$$

Likewise, the absorbance $A_{4}$ of $\mathrm{pH} 4.0, A_{0}$ of $\mathrm{pH} 0$ and $A_{7}$ of $\mathrm{pH} 7.0$ were measured at arbitrary wavelength and $A_{4}^{\prime}$ was calculated. Successively, the spectrum of PMCPF with quinoid form was obtained from both spectra of PMCPF at pH 3.0 and $\mathrm{pH} 4.0$ as shown in Fig. 4. The overlapping of both spectra at $\mathrm{pH} 3.0$ and $\mathrm{pH} 4.0$ supported the accuracy of $\mathrm{p} K_{\mathrm{a} 1}$ value.

Protolytic Reactions of PMCPF In strong acid aqueous solutions, the absorbance spectrum having a maximum at $462 \mathrm{~nm}$ should be attributed to the univalent cation species $\mathrm{PMCPF}^{+}$. In the solution of $\mathrm{pH} 4$, the spectrum had two peaks at $460 \mathrm{~nm}$ and $488 \mathrm{~nm}$, which were attributable to the neutral quinoid species PMCPF. In solutions with $\mathrm{pH}$ ranging from 4 to 7, the spectra had an isosbestic point at $492 \mathrm{~nm}$. In alkaline solutions, the spectra had a maximum at $509 \mathrm{~nm}$. Unlike fluorescein, the bathochromic shift seen above $\mathrm{pH} 9$ appeared with the dissociation of the hydroxyl group. The values $\mathrm{p} K_{\mathrm{a} 1}=1.83$ and $\mathrm{p} K_{\mathrm{a} 2}=5.80$ were eventually obtained. However, $\mathrm{p} K_{\mathrm{a} 3}$ and $\mathrm{p} K_{\mathrm{a} 4}$ could not be accurately obtained due to the polyprotonic acid characteristics of PMCPF. From these results, we propose a pathway for the protolytic reactions of PMCPF in aqueous solutions, as shown in Fig. 5. Fluorescence intensity increased with the initial rise in $\mathrm{pH}$, then decreased above $\mathrm{pH} 9$.

Crystal Structure of PMCPF PMCPF was recrystallized from various media. No crystalline product was obtained from methanol or acetone. To increase the viscosity of the medium, 2 to 3 drops of water, DMSO, or $\mathrm{MeSO}_{3} \mathrm{H}$, were added to PMCPF methanol solution, and recrystallization was accomplished at $16^{\circ} \mathrm{C}$. From the $\mathrm{MeSO}_{3} \mathrm{H}$ and methanol solution, the compound solidified to form a thin orange crystal, a portion of which was used for X-ray analysis.

The molecular structure of PMCPF was determined by $\mathrm{X}$-ray crystallography. A hydrogen-bonded acceptor-donor crystal $\left[\mathrm{PMCPF}^{+}\right]\left[\mathrm{MeSO}_{3}^{-}\right]$was obtained when the molar ratio of $\mathrm{PMCPF} / \mathrm{methanesulfate}$ was $1 / 1$. The molecule consisted of both xanthene and benzene moieties. The two moieties were linked by a C9-C6' single bond of length

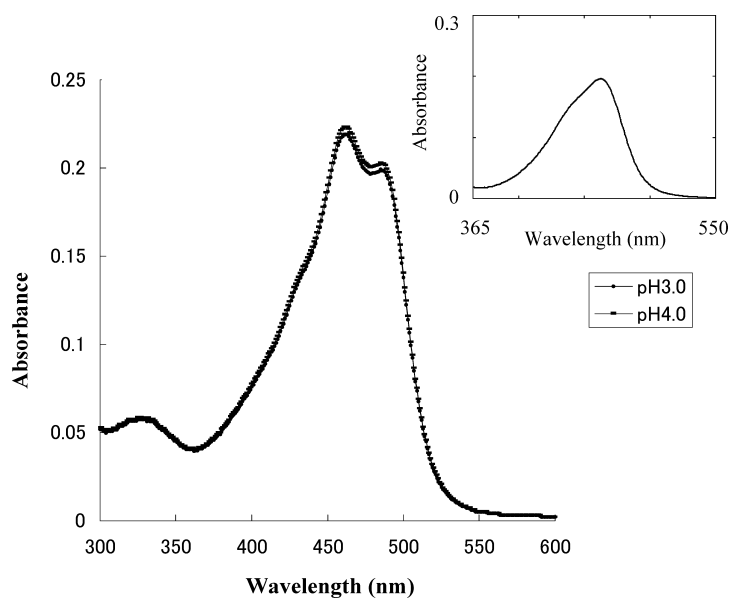

Fig. 4. Absorption Spectra of PMCPF with Quinoid Form Inset; Absorption spectra pf PMCPF with cationic form.
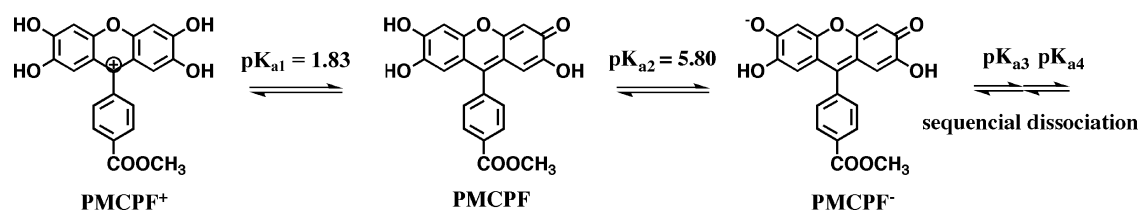

Fig. 5. Proposed Protolytic Reactions of PMCPF 


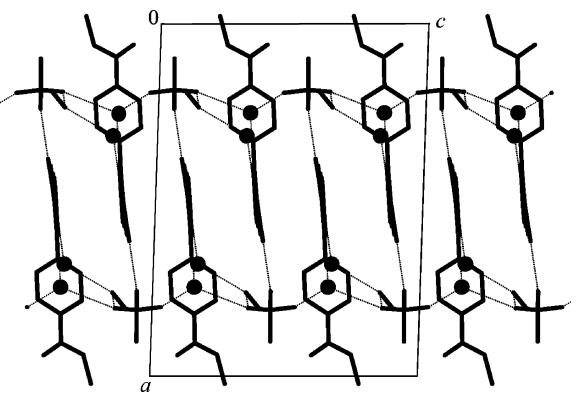

Fig. 6. Hydrogen Bonding Network of PMCPF Viewed along the Crystallographic $b$ Axis

1.479(6) $\AA$. The three rings in the xanthene moiety had a high degree of planarity. The benzene moiety was almost perpendicular to the xanthene moiety, where the interplanar angle was $64.9(2)^{\circ}$. The xanthene moiety had four $\mathrm{OH}$ groups at 2, 3, 6, and 7 positions. The bond lengths of $\mathrm{C} 2-\mathrm{O} 2, \mathrm{C} 3-\mathrm{O} 3, \mathrm{C} 6-\mathrm{O} 6$, and $\mathrm{C} 7-\mathrm{O} 7$ were $1.359(5)$, $1.329(5), 1.342(5)$, and 1.342(5) $\AA$, respectively, and were larger than $1.31 \AA$ assigned to $\mathrm{C}-\mathrm{OH}$. The $\mathrm{C}-\mathrm{C}$ bond lengths in the xanthene moiety were $1.36-1.42 \AA$, which were shorter than $1.51 \AA$ typical of alkanes.

Figure 6 shows a network of hydrogen bonds. Within each $\mathrm{PMCPF}$ molecule, intermolecular $\mathrm{C}=\mathrm{O} \cdots \mathrm{H}-\mathrm{O}$ hydrogen bonds were involved in the three hydrogen bonds of this type. Of the three intermolecular hydrogen bonds per PMCPF, two were formed with neighboring PMCPF in the same layer. It was found that $\mathrm{MeSO}_{3} \mathrm{H}$ donated a proton to the xanthene moiety through hydrogen bonding.

Figure 6 is a $b$ axis projection of the packing arrangement with methanesulfate. The xanthene moiety was partially stacked, parallel to each other. From these results, the electronic interaction between the xanthene moiety and the benzene moiety could not be confirmed, compared to SPF, which suggested that the conjugated system between the two moieties is independent.

\section{Conclusion}

Protolytic equilibria in aqueous solutions of PMCPF were studied by spectrophotometric estimation of the $\mathrm{p} K_{\mathrm{a}}$ values. Successively, identical spectra of PMCPF with quinoid form was obtained. The behavior of fluorescein in aqueous solution is expected to be simple, through the selection of the types and positions of the functional group on the benzene moiety. In addition, this study has provided the first evidence of the crystal structure of the proton acceptor form of a fluorescein derivative. The future direction of this study will be the elucidation of fluorescence properties in relation to $\mathrm{pH}$.

Acknowledgement This research was supported by a Grant-in-Aid for High Technology Research from the Ministry of Education, Culture, Sports, Science and Technology of Japan. We would like to thank Ms. Mihoyo Fujitake and Dr. Katsuhiko Minoura of Osaka University of Pharmaceutical Sciences for MS and NMR measurements.

\section{References}

1) Kamiya M., Kobayashi H., Hama Y., Koyama Y., Bernardo M., Nagano T., Choyke P. L., Urano Y., J. Am. Chem. Soc., 129, 3918 3929 (2007).

2) Kawasaki K., Sakakibara K., Bull. Chem. Soc. Jpn., 80, 358-364 (2007).

3) Osborn R. S., Rogers D., Acta Cryst., B31, 359-360 (1975).

4) Markuszewski R., Diehl H., Talanta, 27, 937-946 (1980).

5) Yamaguchi K., Tamura Z., Maeda M., Acta Cryst., C53, 284-285 (1997).

6) Tremayne M., Kariuki B. M., Harris K. D. M., Angew. Chem. Int. Ed., 36, 770-772 (1997).

7) Knudsen K. D., Pattison P., Fitch A. N., Cernik R. J., Angew. Chem. Int. Ed., 37, 2340-2343 (1998).

8) Chen S. C., Nakamura H., Tamura Z., Chem. Pharm. Bull., 27, 475479 (1979).

9) Tamura Z., Morioka T., Maeda M., Tsuji A., Bunseki Kagaku, 43, 339-345 (1994).

10) Jang Y. H., Hwang S., Chung D. S., Chem. Lett., 30, 1316-1317 (2001).

11) Mchedlov-Petrossyan N. O., Vodolazkaya N. A., Surov Y. N., Samoylov D. V., Spectrochim. Acta, Part A, 61, 2747-2760 (2005).

12) Kamino S., Doi M., Yamaguchi T., Tominaga H., Amano E., Umehara S., Naito M., Yamazaki C., Fujita Y., Anal. Sci., 22, x35-x36 (2006).

13) Kamino S., Yamaguchi T., Mori T., Miyamoto M., Kusumi Y., Fujita Y., Anal. Sci., 21, 1549-1552 (2005).

14) Albert A., Serjeant E. P., "The Determination of Ionization Constants," 3rd ed., Chapman and Hall Ltd., New York, 1984. 